\title{
Contractual Aspects in the Utilisation of Level Two Building Information Modelling (BIM) within Malaysian Public Construction Projects
}

Mohamad Izani Ahmad Kamal Hasni, Zulhabri Ismail*, and Norfashiha Hashim

Faculty of Architecture, Planning and Surveying, Universiti Teknologi MARA (UiTM), 40450, Shah Alam, Selangor, Malaysia

\begin{abstract}
Building Information Modelling (BIM) is a technology and process that are transforming way of designing, constructing, operating and using the building or facility. In essence, BIM models is a platform for collaboration as it encourages intensive communication and interdependence among multidisciplinary project members. In Malaysia's BIM Guide, this collaborative process can be seen in Level 2 BIM Maturity which all designers engaged in projects work together to create a single computer-generated 3D Model. From this process, many benefits that BIM promises such as clash free construction, quality of design and greater certainty could be achieved. Therefore, the Malaysian Government announced the implementation of at least $40 \%$ of Level 2 BIM for public projects costing RM100 million and above in 2019. However, despite mutual understanding between construction players, the full integration of BIM in the project lifecycle seems to be a daunting task. In the context of the Malaysian Public Sector, many uncertainties could arise pertaining to legal and contractual matters i.e. whether or not the existing contractual instruments are able to support the collaborative environment and digital information sharing that Level 2 BIM engenders. This paper presents a narrative review of published literature on the concept of Level 2 BIM and contractual consideration based on the utilisation of BIM within Malaysian Public construction projects, which includes books, government publications, conference presentation slides, newspaper articles and paper-based journal articles. This paper concludes that in order to legitimise multidisciplinary collaboration and integration of information in BIM within existing standard forms of contract, the development of a contract protocol and suitable procurement model are necessary.
\end{abstract}

\section{Introduction}

The Malaysian Construction Industry (MCI) aims to be empowered and strengthened through the Construction Industry Transformation Programme (CITP) [1] and the Eleventh Malaysia Plan [2]. The uptake of Information and Communications Technology (ICT) would transform the nation's construction industry into a highly productive and environmentally sustainable industry [3]. Building Information Modelling, better known as BIM, is recognised as an advanced ICT measure, which has the potential to transform the construction industry by enhancing efficiency, productivity, and quality [4]. Furthermore, Industrial Revolution 4.0 will bring significant changes to the construction ecosystem through the uptake of information and digital technology [5]. Therefore, the role of BIM is crucial in supporting the quest for digitalisation of the construction industry.

A fundamental approach to BIM implementation in Malaysia is given in the BIM Guide, which was formulated to provide directives, references, and process guidelines for construction players [6]. The Guide provides a detailed explanation for each maturity level and implementation process in Malaysia. Each level is

*Corresponding author: zulhabri@salam.uitm.edu.my differentiated by the level of information collaboration based on specific types and processes [7]. As stated in CITP [1], the industry aims to achieve Level 2 BIM maturity implementation by 2020 in which a minimum of $40 \%$ implementation rate of public projects valued at RM100 million and above shall be implemented by the corresponding approaches and processes by 2019 [8]. However, according to the National BIM Report [9] in Malaysia, the industry implementation is still between Level 0, which are still using 2D and Computer-Aided Drafting (CAD) based and Level 1 which are only single disciplinary use of 3D modelling. Therefore, the implementation is limited to design stage and specific professions only. Further research is required to address the barriers that hinder the widespread adoption of BIM, especially towards the implementation of Level 2 in Malaysia. One commonly identified barrier is the legal and contractual aspects surrounding BIM implementation [10].

Therefore, this paper aims to explore the concept of Level 2 BIM and the legal and contractual implications within the context of the Malaysian Public Sector. This review will support the preparation of a suitable contractual requirement for the successful adoption of 
Level 2 BIM within the context of the Malaysian Public Sector.

\subsection{Research Methodology}

This paper uses a narrative literature review based on recent publications from books, government publications, presentation slides, newspaper articles and electronic or paper-based journal articles relating to BIM. The aim of the paper is to review the concept of BIM and the legal and contractual implications in reaching out Level 2 BIM within the context of Malaysian Public Sector. Through a narrative review, the author was able to describe and discuss the scientific state of a specific topic [11]. However, this type of review does not list the types of databases and methodological approaches nor the evaluation criteria for inclusion of articles during database search [12]. Nevertheless, this paper provides a preliminary review to distinguish what has been achieved and the key areas of BIM in the Malaysian context. To find articles, the following words have been used in scientific databases: 1. BIM 2. BIM Legal 3. BIM Contractual 4. BIM Collaboration 5. BIM Level 2.

\subsection{Building Information Modelling}

The National BIM Steering Committee defines BIM as, "a modelling technology and associated set of processes to produce, communicate, analyse, and the use of digital information models throughout the construction project life-cycle". In other words, BIM technology can potentially transform the conventional way of designing, constructing, and operating a building [13]. Eastman et al. [14] emphasised on the concept of BIM as the creation of digital physical representations, which can be shared through an agreed platform among project participants. The BIM model can act as an integrated project data repository [15] in which analysis can be done using intelligent parametric objects [14]. The level of BIM application within an organisation or industry is measured using a maturity assessment. In Malaysia, the maturity level or stage is divided into four, which are Level 0, Level 1, Level 2, and Level 3 [6].

\subsubsection{Level 2 BIM}

Maturity level is used to determine the application of BIM within an industry or organisation [16]. The level is categorised according to the output of the model, process, and environment [6]. As shown in Table 1, Level 2 BIM is illustrated as, "a sharing object-based model involving data between two or more disciplines". This level requires the collaboration of $3 \mathrm{D}$ models and digital information from different project disciplines [17]. The information can be shared and communicated through agreed common platforms [18]. Therefore, this process would promote a collaborative process, which would benefit project performance [19]. However, as compared to Level 0 and Level 1, the adoption of Level 2 is more challenging, as it involves a variety of issues and considerations [20]. Therefore, common standards are important to ensure collaboration and digital information sharing can be done in a common data environment.

Table 1. BIM Stages [6]

\begin{tabular}{|l|l|l|}
\hline Level & Keywords & Description \\
\hline Level 0 & Manual & $\begin{array}{l}\text { 2D Manual and CAD-Based } \\
\text { (2D or 3D) }\end{array}$ \\
\hline Level 1 & Modelling & $\begin{array}{l}\text { Single disciplinary use of } \\
\text { object-based 3D modelling } \\
\text { software within one discipline }\end{array}$ \\
\hline Level 2 & Collaboration & $\begin{array}{l}\text { Sharing Object based models } \\
\text { and data between two or more } \\
\text { disciplines }\end{array}$ \\
\hline Level 3 & Integration & $\begin{array}{l}\text { Integration of several } \\
\text { multidisciplinary models and } \\
\text { data using model server or } \\
\text { other network-based } \\
\text { technologies }\end{array}$ \\
\hline
\end{tabular}

\subsection{Malaysian Public Sector}

The Malaysian construction industry had initiated the implementation of BIM since the early 2000s through the Private Sector [21]. Later, the idea to implement $\mathrm{BIM}$ in public projects was introduced by the Director of Public Works Department (PWD) in 2007 [22]. Since then, BIM has become a buzzword in the Malaysian construction industry. The BIM committee in PWD was formed by the Government on 27 August 2007 to choose a suitable BIM platform and ensure its interoperability [23]. Besides that, the committee also published a standard manual documentation as a guideline or reference, and since 2011 has provided BIM training and advisory assistance for project teams using BIM tools. In 2009, the first BIM conference was held to encourage construction players to adopt Information and Communications Technology [24]. This describes the motivation of the Government to adopt the latest technology, especially BIM [25]. The inclusion of BIM under the main thrust of CITP has given a wakeup call to industry players to adopt BIM [1]. As shown in Table 2, several projects have been initiated by PWD to utilise Level 2 BIM, for example, the Putrajaya National Cancer Institute, the Malaysian Anti-Corruption Commission (MACC), the Faculty of Electrical \& Electronic Engineering, Universiti Tun Hussein Onn Malaysia (UTHM), and the Maran Health Clinic (Type 5), Maran, Pahang [26]. 
Table 2. Completed PWD BIM Compliant Project [26]

\begin{tabular}{|l|l|}
\hline \multicolumn{1}{|c|}{ Project } & \multicolumn{1}{c|}{ Initiative } \\
\hline $\begin{array}{l}\text { National Cancer Institute } \\
\text { (NCI) Putrajaya }\end{array}$ & Pilot Project \\
\hline $\begin{array}{l}\text { Academic Block, Sekolah } \\
\text { Kebangsaan Meru Raya, } \\
\text { Ipoh, Perak }\end{array}$ & Pilot Project \\
\hline $\begin{array}{l}\text { Academic Block, Sekolah } \\
\text { Kebangsaan Tanjung Minyak } \\
\text { 2, Melaka }\end{array}$ & Pilot Project \\
\hline $\begin{array}{l}\text { Malaysia Anti-Corruption } \\
\text { Commission (MACC) Shah } \\
\text { Alam, Selangor }\end{array}$ & \\
\hline $\begin{array}{l}\text { Maran Health Clinic (Type } \\
\text { 5), Maran, Pahang }\end{array}$ & Pilot Project \\
\hline Science Lab, MARA College & Pilot Project \\
Banting, Selangor & BIM Project \\
\hline
\end{tabular}

From 2019, public projects worth RM100 million and above would be required to apply the BIM system in Level 2 [8]. This level promotes a more integrated operation in a collaborative environment and encourages sharing of information digitally [27]. In this case, the gap in contractual aspects has been recognised as one of the primary barriers to achieving this end [28]. On the BIM Day 2018, a Royal Institution of Surveyors Malaysia (RISM) Legal Committee was established to deal with legal and contractual issues. However, in order to provide suitable contractual supports, more research is needed to understand the legal issues and contractual considerations surrounding the implementation of Level 2 BIM within the context of the Malaysian Public Sector.

\section{Legal Issues and Contractua Considerations}

This paper first reviewed the concept of BIM and Leve 2 Maturity Stages with the development of BIM in the context of Malaysian public sector. In this section, it presented legal issues and contractual considerations pertaining the uptake of Level 2 BIM. Many of studies had provides an extensive review on the contracting issues with uptake of BIM [29][30][31][32].

\subsection{Integrity of Shared Information}

In Level 2 BIM, the model contributor and designer needs to provide data and information for the development of the model [18]. The integrity of shared information is crucial to ensure the quality and richness of the model in achieving the agreed BIM objectives [33]. As described in RW Vaught Co. v FD Rich Co. ${ }^{\mathrm{a}}$ the input of information will have a significant impact on the contractual performance and project delivery [34][35]. Furthermore, all parts of the contract should articulate the modelling deliverables, especially relating

${ }^{\text {a }} R W$ Vaught Co. $v$ FD Rich Co, 439 F.2d 895 (Courts of Appeal 1971) to the necessary data and information for the development of the BIM model [36]. Thus, as Level 2 BIM demands collaboration and openness, the integrity of shared information from the contributor must be considered.

\subsection{Legal Liabilities}

The nature of Level 2 BIM requires the involvement of multiple contributors, software vendors, clients, and more [6]. There are uncertainties in the legal liabilities and obligations among parties in the contract and in supporting this level of implementation [33]. Based on the doctrine of privity of contract, a third party cannot enforce conditions of a contract between the primary parties to the contract [37]. This would conflict with the principle of BIM in which the model should allow unrestricted flow of information. On the other hand, the liability of the software vendor as presented in the case of MA Mortensen Co. $v$ Timberline Software Corporation $^{\mathrm{b}}$ should also be considered [34][35]. Therefore, an unclear liability among the involved parties would lead to difficulties in allocating compensation of effort and risk associated with BIM [36].

\subsection{Standard of Care}

The essence of Level 2 BIM allows the model and digital information to be shared and communicated among parties [6][33]. There can be no legal liability for professional negligence unless there has been a breach of duty of care owed to some persons [38]. In Level 2 BIM, each contributor has sufficient proximity and is responsible for any input because he or she is aware of the design intent and the client's requirement regarding the final product [39]. Although the contributor may not be liable for unauthorised use of others who have access and rights to the model, there is still a duty of care, which is to provide quality information [40]. The contributors could be liable for the flaws in the BIM platform if the contractual terms mandate the contributors to review the BIM's output and locate any incompatibility [41]. The conditions of contract should explain the contractual relationship, modelling deliverables, collaboration, and appropriate punitive measures for non-performance of a BIM-compliant project [36]. Therefore, without the systemic legal supports, the blame would be shifted between the parties in the event of any related disputes.

\subsection{Electronic-based Documents}

In conventional project delivery, the design and documentation are non-parametric, paper-based, and operates in a fragmented environment [42]. However, Level 2 BIM induces collaboration through the integration of a federated model among contributors [6].

${ }^{\mathrm{b}}$ MA Mortensen Co. v Timberline Software Corporation, 970 P.2d 803, 93 Wash. App. 819 (Ct. App. 1999) 
Thus, a concern arises on the admissibility of digital documents in the contract. In the case of FXCM Securities Ltd v Michael John Digby ${ }^{\text {c }}$ (2013), computerbased evidence is considered as third-hand hearsay and electronic notice can only be considered as a substitute for written notice, if it has been received [34][35] Therefore, there is a need to clarify the authenticity, validity, and liability of admissible electronic documents. Other concerns on e-documents is the breach in data security [36]. The data must be protected agains any possible loss, manipulation, and corruption. Despite this fact, the interoperability between systems is considered part of the legal issue. The software must be able to process the data transfer between project stakeholders and assign responsibility for managing, monitoring, and auditing the process [36]

\subsection{Contract Document}

The contract documents consider drawings, which detail the design and specifications, as part of the construction of contract documents. However, because the BIM or digital model can possibly be included in the submission of shop drawings, there is a limited approach that integrates BIM as part of the contract document. The contract needs to permit e-contracting and ecommunication to ensure the project can transpire in digital environment [36]. Besides that, the legislation requires the approval to be made in writing such as "stamped" drawings and specifications. Dougherty [35] highlighted that there is a bidirectional relationship between BIM and the two-dimensional drawing that allows the amendment of either the model or projected drawings. In Level 2 BIM, many requirements and terms need to be highlighted in the contract to ensure implementation such as compensation involved, collaboration among parties, model status, BIM deliverables and punitive measures [29]. Therefore, mos countries use the BIM protocol as a supporting document to provide contractual links and support implementation.

\subsection{Intellectual Property (IP) and Ownership}

The intellectual property of the design and data lies with the designer [43]. The IP considers the source of information embedded in the model. Apart from that, development of the Level 2 BIM model requires contribution from multiple contributors [6]. This process has raised concerns among the contributors regarding ownership of the completed model. The infringement of data and copyright are among the issues that could arise from the implementation. In Attia Architects $v$ New York Hospital $^{4}(1998)^{\mathrm{d}}$, infringement of the ideas of design and concept was found to occur in the construction projects between the designer and the extent of what is

${ }^{c}$ FXCM Securities Ltd v Michael John Digby England and Wales High Court (Commercial Court 2013)

d Attia Architects $v$ New York Hospital, US Court of Appeals for the Second Circuit - 201 F.3d 50 (2d Cir 1999) considered as the infringement of copyright [34][35] Therefore, the entitlement for the extent of use of data and developed model, ownership, and licence should be agreed upon earlier in the contract [44].

\subsection{Roles and Responsibilities}

The fundamental changes in Level 2 BIM will encompass the roles and responsibilities of the project participants [45]. The increased collaboration in BIM will impact the conventional design process and responsibility of the design [35]. As illustrated in Wynner $v$ Buxton $^{\mathrm{e}}$ (1979), the court of appeal held the architect liable for the civil engineering plans, which does not include other engineering disciplines [34][35]. This would raise uncertainties, as the BIM involves multiple contributors from different disciplines. Furthermore, the roles and responsibilities of each party must be stated clearly in the contract. Trant Engineering Ltd $v$ Mott MacDonald Ltd ${ }^{\mathrm{f}}$ (2017) highlighted the impact of having a clear understanding on the contractual terms between the involved parties [46].

\section{Discussion}

There are four levels of BIM maturity, which reflect the level of project collaboration, level of technology, and the ability to exchange information digitally [6]. In Malaysia, Level 2 BIM will be made compulsory for each public project worth RM100 million and above by 2019 [1][8]. Based on the National BIM Report [9], statistics show that the utilisation of BIM is still limited to the design stages and certain professions. Thus, clear understanding is needed among construction players to prepare themselves for Level 2 BIM. In Level 2, BIM is described shortly as a sharing object-based model with data involving two or more disciplines [6]. This creates a new collaborative environment compared to conventional delivery approaches [47]. The implicit result of the implementation of BIM (especially in Levels 2 and 3 ) is a change in the relationship between the members of the project coalition, and a greater emphasis on collaboration [14]. However, most issues and considerations arise as the uptake of BIM moves to another level of implementation [20]. This environment requires a new contractual arrangement to address the shift from fragmented delivery to integrated delivery. Besides that, it is crucial to address legal and contractual disputes to remove legal risks when working on collaborative projects [48]. Therefore, there is a need to revisit the construction and contract law that governs activities within the construction industry [49]. Recently, the RISM legal committee was established to provide support in dealing with the legal and contractual aspects for the implementation of another level of BIM. In the

e Wynner v Buxton, Civ. No. 55474. Second Dist., Div. Three, 1979

${ }^{\mathrm{f}}$ Trant Engineering Ltd $v$ Mott MacDonald Ltd, WHC 2061 (TCC, 2017) 
context of the Malaysian Public Sector, there is a need to examine the standard form of contract, contractual protocol, and procurement to support Level 2 BIM.

\subsection{Standard Form of Contract (SFC)}

A construction contract can be defined as the agreement between one person and another regarding the construction works that need to be carried out [37]. In the implementation of BIM, the construction contract needs to be able to support the engendered collaborative process and digital information sharing [50]. The standard form of contract (SFC) in Malaysian public projects comprise JKR Form 203, Form 203A, and Forms $203 \mathrm{~N}$ and 203P [37]. This SFC was developed before the emerging application of BIM within the Malaysian construction industry [28]. Therefore, it tends to insulate and isolate rather than actively support collaboration and digital information sharing [40]. Many studies have highlighted the need to provide adequate contractual provision among project participants towards the full use of Level 2 BIM [50][36][51][52]. Clear contract terms would prevent gaps in liability, induce clear allocation of risk and roles, and promote better understanding between contracting parties [53]. In short, more research is needed to revisit the JKR or PWD contract forms, so as to examine their compatibility with the implementation of Level 2 BIM.

\subsection{Form, Document, and Guidelines}

The implementation of Level 2 BIM could lead to massive confusion, inconsistencies, misunderstandings, and gaps among construction players [20]. Therefore, form, document, and guidelines are important to provide support for the standard process and practice that the utilisation of BIM engenders [54]. Written forms should comprise client requirements, early team agreement, an overall legal framework for a BIM-based project, collaboration requirements, and Governmental rules and regulations [35]. This would enhance information trust, clarify ownership, and address concerns on intellectual property rights. BIM protocols are important for providing a contractual link between the current SFC and the new collaborative and information requirements brought about by BIM [53]. In Malaysia, PWD has established several supporting documents and guidelines to ease the implementation of BIM in Public Sectors, fo example PWD BIM Guidelines, PWD BIM Standards, PWD Manual Working Process, and PWD BIM Requirements [26]. The PWD BIM Requirements for the Design and Build of Public Projects are considered a contractual protocol for the implementation of BIM in public projects. However, this document only focuses on the design and build of public projects. Besides that none of these documents published by PWD discussed in detail the level of implementation or maturity stages of BIM in public sectors. Several supported clauses for implementation must still be provided based on the understanding of Level 2 BIM to deal with surrounding legal and contractual issues. Therefore, the contractual protocol must include all necessary features that are appropriate for the application of BIM within the context of the Malaysian Public Sector.

\subsection{Procurement Method}

As documented in much of the literature, BIM provides a consolidated platform to allow collaborators to communicate and integrate, especially for Level 2 BIM. Therefore, collaborative procurement methods are conducive for the successful adoption of BIM. Despite this fact, optimal BIM performance requires similar levels of technology and skill development [49]. Increasing globalisation and developing collaboration such as IPD (Integrated Project Delivery), project partnering, and strategic alliances would increase interorganisational communication and the development of information exchange via the use of IT tools such as BIM [40][51]. Therefore, these procurement methods would promote early collaboration that is crucial for successful BIM adoption.

\section{Conclusion}

The full benefits of using Level 2 BIM can only be achieved if the project participants work collaboratively and allow for the integration of information throughout the project lifecycle. Uncertainties may arise on whether legal and contractual consideration have manifested in the contractual provision and procurement. Therefore, many studies have highlighted the need to redevelop existing relationships and responsibilities among the project participants to ensure successful BIM adoption. However, the progress towards realising contractual support for Level 2 BIM and an integrated delivery process in Malaysia has been markedly slow. Furthermore, the absence of explanation on the level of implementation or maturity stages in the published PWD documents would lead to confusion among the practitioners. In sum, the construction contract, common standards and documents, and suitable procurement would help in dealing with the surrounding legal and contractual considerations. This on-going research is expected to produce a contractual protocol for Level 2 BIM implementation in the Malaysian Public Sector. This research articulates the discrete relationship between construction contracts, the legal and commercial environment, circumstances and behaviours that create barriers to BIM collaboration and information sharing, or Level 2 BIM.

\section{References}

1. [1] CIDB, "Construction Industry Transformation Programme (CITP) 2016-2020," Construction Industry Development Board Malaysia. pp. 1-184, 2015.

2. [2] Economic Planning Unit, "Eleventh Plan 
2016-2020 Malaysia Anchoring Growth on People," Percetakan Nasional Malaysia Berhad. p. 262, 2015.

3. [3] S. K. Chew, "Evolution of Construction Industry: To the Trend of Technology Based Industry," 2015.

4. [4] W. Wang and R. Han, "A review of Building Information Modelling," in AIP Conference Proceedings 1967, 040058 (2018), 2018, pp. 1-4.

5. [5] M. King, "How Industry 4 . 0 and BIM are Shaping the Future of the Increasing Information in," 2017. [Online]. Available: https://www.giminternational.com/content/article/how-industry-4-0 and-bim-are-shaping-the-future-of-theconstruction- environment. [Accessed: 12-May2018].

6. [6] CIDB, BIM GUIDE 1: Awareness. Construction Industry Development Board (CIDB), 2016 .

7. [7] Z. A. Hamid et al., "Building Information Modelling (BIM) Stage 2 Implementation Strategy for the Construction Industry in Malaysia," EConstruct Building Information Modelling Magazine, pp. 22-27, 2017.

8. [8] P. W. Iskandar, "Penggunaan Level 2 BIM menjelang 2019," Berita Harian Online, Alor Setar, Kedah, Malaysia, 2018.

9. [9] Construction Industry Development Board of Malaysia, "BIM report 2016." pp. 1-43, 2016.

10. [10] S. Ahmed, "Barriers to Implementation of Building Information Modeling ( BIM ) to the Construction Industry: A Review," J. Civ. Eng. Constr., vol. 2, pp. 107-113, 2018.

11. [11] M. J. Grant and A. Booth, "A typology of reviews: An analysis of 14 review types and associated methodologies," Health Info. Libr. J., vol. 26, no. 2, pp. 91-108, 2009.

12. [12] E. T. Rother, "Systematic literature review $\mathrm{X}$ narrative review," ACTA Paul. Enferm., vol. 20, no. 2, pp. 7-8, 2007

13. [13] S. Azhar, M. Khalfan, and T. Maqsood, "Building information modelling (BIM): now and beyond," Constr. Econ. Build., vol. 12, no. 4, pp. 15-28, 2015.

14. [14] C. Eastman, P. Teicholz, R. Sacks, and K. Liston, BIM Handbook: A Guide to Building Information Modelling for Owners, Managers, Designers, Engineers and Contractors. 2011.

15. [15] S. Patil and P. M. Khandare, "Application of BIM for Scheduling and Costing of Construction Project,” pp. 1644-1647, 2017.

16. [16] H. S. Jayasena and C. Weddikkara, "Assessing the BIM Maturity in a BIM Infant Industry," Second World Constr. Symp. 2013 Socio-Economic Sustain. Constr., no. June 2013, pp. 62-69, 2013.

17. [17] A. Z. Sampaio and E. Berdeja, "Collaborative BIM environment as a support to conflict analysis in a building design," pp. 77-82, 2017.

18. [18] W. Lu, D. Zhang, and S. Rowlinson, "BIM Collaboration : a Conceptual Model and Its Characteristics," Procs 29th Annu. ARCOM Conf., no. September, pp. 25-34, 2013.

19. [19] B. Succar, "Building information modelling framework: A research and delivery foundation for industry stakeholders," Autom. Constr., vol. 18, no 3, pp. 357-375, May 2009

20. [20] A. Bataw, R. Kirkham, and E. Lou, "The Issues and Considerations Associated with BIM Integration," MATEC Web Conf., vol. 00005, pp. $1-8,2016$

21.[21] A. A. Latiffi, S. Mohd, and J. Brahim, "Application of Building Information Modeling (BIM) in the Malaysian Construction Industry: A Story of the First Government Project," Appl. Mech. Mater., vol. 773-774, no. MARCH, pp. 943-948, 2015

22.[22] N. Zainon, F. A. Mohd-rahim, and H. Salleh, "The rise of BIM in Malaysia and its impact towards quantity surveying practices," MATEC Web Conf., vol. 66, p. 00060, 2016.

23. [23] A. Ahmad Latiffi, J. Brahim, S. Mohd, and M. S. Fathi, "The Malaysian Government's Initiative in Using Building Information Modeling ( BIM ) in Construction Projects," in ASEA-SEC 2, Bangkok, 2014, no. November.

24. [24] A. N. Harun, S. A. Samad, M. N. M. Nawi, and N. A. Haron, "Existing Practices of Building Information Modeling ( BIM ) Implementation in the Public Sector," Int. J. Supply Chain Manag., vol. 5, no. 4, pp. 166-177, 2016.

25. [25] A. T. Haron, A. J. Marshall-Ponting, Z. Zakaria, M. N. M. Nawi, Z. A. Hamid, and K. A. M. Kamar, "An industrial report on the Malaysian building information modelling (BIM) taskforce: Issues and recommendations," Malaysian Constr. Res. J., vol. 17, no. 1, pp. 21-36, 2015.

26. [26] M. F. Shapiai, "Managing BIM in Goverment Project [Presentation Slides].” Level 11, Sunway Putra Tower, Lot 100, Jalan Putra, 50350 Kuala Lumpur, 2018.

27. [27] A. Croft and N. Ledger, "BIM promotes collaboration," Constr. Law J., vol. 26(5), no. June 2015, pp. 23-25, 2015.

28. [28] Q. J. Keat, "Issues in BIM for QS: Outcomes from the Quantity Surveyor (QS) Principals Dialogue," RISM, no. 1, pp. 18-20, Jul-2017.

29. [29] A. H. Abd Jamil and M. S. Fathi, "Contractual challenges for BIM-based construction projects: a systematic review," Built Environ. Proj. Asset Manag., p. BEPAM-12-2017 0131, 2018.

30. [30] C.-N. Bodea and A. Purnus, "Legal Implications of Building Information Modeling," 2008.

31. [31] E. Nulton, "Analysis of legal concepts for 
projects implementing BIM in the US," Pennsylvania State University, 2013.

32. [32] M. A. B. Chou-Duivis, "Some legal aspects of BIM in establishing a collaborative relationship," in Management and Innovation for a Sustainable Built Environmentc (MISBE 2011), CIB International Conference, Amsterdam, 2011, no. June.

33. [33] H. Ashcraft, "Building information modeling: A framework for collaboration," BIM-legal, vol. 28 , no. 3, pp. 1-14, 2008

34. [34] A. Alwash, P. E. D. Love, and O. Olatunji, "Impact and Remedy of Legal Uncertainties in Building Information Modeling," J. Leg. Aff. Disput. Resolut. Eng. Constr., vol. 9, no. 3, p. 04517005, 2017.

35.[35] J. M. Dougherty, "Claims, Disputes and Litigations Involving BIM.” Routledge, pp. 103$126,2015$.

36. [36] A. Manderson, M. Jefferies, and G. Brewer, "Building Information Modelling and Standardised Construction Contracts : a Content Analysis of the GC21 Contract Legal and Contractual Concerns with BIM Deployment," Constr. Econ. Build., vol. 15 , no. 3, pp. 72-84, 2015.

37. [37] S. Rajoo and H. S. KS, "Construction Law in Malaysia.” pp. 88-90, 2012.

38. [38] L. M. Pheng and I. J. Detta, "Business LawSecond Edition.” Oxford University Press, pp. 265-266, 2014.

39. [39] D. B. Arensman and M. E. Ozbek, "Building Information Modeling and Potential Legal Issues," Int. J. Constr. Educ. Res., vol. 8, no. 2, pp. 146156, 2012.

40. [40] O. A. Olatunji, "Views on building information modelling, procurement and contract management," Proc. Inst. Civ. Eng. - Manag. Procure. Law, vol. 167, no. 3, pp. 117-126, 2014

41.[41] T.-Y. Hsieh, J.-H. Chen, and K.-M. Hsu, "Legal risks incurred under the application of BIM in Taiwan," Proc. ICE - Forensic Eng., vol. 168, no. 3, pp. 127-133, 2015

42. [42] M. N. Mohd Nawi, N. Baluch, and A. Y. Bahauddin, "Impact of Fragmentation Issue in Construction Industry: An Overview," MATEC Web Conf., vol. 15, p. 01009, 2014.

43. [43] O. A. Olatunji, "A preliminary review on the legal implications of BIM and model ownership," Electron. J. Inf. Technol. Constr., vol. 16, no. August 2010, pp. 687-696, 2011.

44. [44] A. Chen, "BIM from a practical perspective," no. March 2014, pp. 28-35, 2016.

45. [45] Ö. Onur, "Changing Role(S) of the Profession of Architecture: Building Information Modeling in Practice," Middle East Technical University, 2015.

46. [46] F. Elliott, "The first reported UK BIM case: Trant v Mott MacDonald,” 2018. [Online]

\section{Available:}

https://www.fenwickelliott.com/researchinsight/annual-review/2017/uk-bim-trant-mottmacdonald . [Accessed: 15-Sep-2018].

47. [47] I. Czmoch and A. Pękala, "Traditional design versus BIM based design,” Procedia Eng., vol. 91, no. TFoCE, pp. 210-215, 2014.

48. [48] E. Alreshidi, M. Mourshed, and Y. Rezgui, "Factors for effective BIM governance," J. Build. Eng., vol. 10, no. February, pp. 89-101, 2017.

49. [49] A. Alwash, P. E. D. Love, D. Ph, D. Sc, O. Olatunji, and D. Ph, "Impact and Remedy of Legal Uncertainties in Building Information Modeling," pp. 1-7, 2016.

50. [50] I. Kuiper and D. Holzer, "Rethinking the contractual context for Building Information Modelling (BIM) in the Australian built environment industry," Australas. J. Constr. Econ. Build., vol. 13, no. 4, pp. 1-17, 2013.

51. [51] D. Mosey et al., "Enabling BIM Through Procuremnt and Contracts," 2016.

52.[52] H. Chong, S. Fan, M. Sutrisna, S. Hsieh, and C. Tsai, "Preliminary Contractual Framework for BIM-Enabled Projects," 2014.

53. [53] M. Winfield and S. Rock, "The Winfield Rock Report. Overcoming the legal and contractual barriers of BIM," no. 1, pp. 11-35, 2018.

54. [54] R. Sacks and U. Gurevich, "a Review of Building Information Modeling Protocols, Guides and Standards for Large Construction Clients," $J$. Inf. Technol. Constr., vol. 21, no. 21, pp. 479-503, 2016. 